Another analysis shows a maximum error of $6 \%$ in the element present, in the greatest quantity, when the total quantity of the sample was less than $5 \mathrm{~mm}^{3}$.

\begin{tabular}{ccccc} 
"As introduced." & & \multicolumn{2}{c}{ Analysis. } \\
$\mathrm{Mm}^{3}$. & $\%$. & Gas. & $\%$. & $\mathrm{Mm}^{2}$. \\
1.36 & 28.5 & $\mathrm{CO}$ & 32.2 & $\mathrm{I} .59$ \\
2.74 & 57.3 & $\mathrm{H}_{2}$ & $5 \mathrm{I} .3$ & 2.54 \\
0.68 & $\mathrm{I} 4.2$ & $\mathrm{O}_{2}$ & 16.5 & 0.82 \\
4.78 &.. & $\mathrm{All}$ &. & 4.95
\end{tabular}

These tests, representative of a considerable number, show conclusively the degree of accuracy which may be expected from the apparatus described. Since this accuracy is well within the desirable limits for the class of work for which the apparatus was designed, it has been accepted for such work, and has been in active use for some time with very satisfactory results.

The foregoing gives then; a complete description of an apparatus designed for the quantitative analysis of small quantities of gases, its manipulation, and the results of tests made to determine its accuracy. The gases which can be handled are water vapor, carbon dioxide, carbon monoxide, oxygen, hydrogen, nitrogen, and methane. Inert gases will be classed with nitrogen. The apparatus will handle quantities varying from a few cu. mm., equivalent at atmospheric conditions, to probably one cc., but may be designed for any variation in limits.

east Pittsaurgh, Pa.

[Contribution from the Chemical Laboratory of the OHIO State Univirsity.]

\title{
THE OXIDIZING ACTION OF POTASSIUM DICHROMATE AS COMPARED WITH THAT OF PURE IODINE. ${ }^{1}$
}

By CARI R. MCCrosixy.

Received September 3, 1918.

The object of this work has been to study some of the analytical reactions of potassium dichromate in an effort to help determine its status as an analytical standard. The time has been devoted, almost entirely to the study of the oxidation of hydriodic acid by the dichromate, the interest in the work being centered, mainly, in the fact that the salt gives a high titration value, $i$. e., liberates more iodine than its equivalent under the normal conditions of the reaction. Varying these conditions corrects this value in a large degree, yet, it would appear, never wholly corrects it. Our work shows that samples of dichromate from different sources act differently. The experimental evidence we have seems to point to the presence of something in the salt, something to which its

${ }^{1}$ A thesis submitted to the Department of Chemistry of the Ohio State University in partial fulfilment of the requirements for the degree of Doctor of Philosophy. 
abnormal reaction may be attributed, but just what this is still remains an open question.

Wagner ${ }^{1}$ first called attention to the fact that potassium dichromate, when it is compared with such other oxidizing agents as potassium bromate, potassium di-iodate, and potassium chromate acted abnormally, when used to liberate iodine. His results show the dichromate gives values averaging $0.3 \%$ high, giving that excess iodine. Further purification, which was accomplished by recrystallization, did not alter this value. He offers the explanation that the dichromate might catalytically affect the very slow oxidation of hydriodic acid by the oxygen dissolved in the solutions. When carbon dioxide was bubbled through the solutions and the air washed out, theoretical results were obtained.

The recent work of Bruhns ${ }^{2}$ does not confirm that of Wagner. $\mathrm{He}$ claims that Wagner's hypothesis, that of the activating effect of the dichromate on the dissolved oxygen, is unjustified, inasmuch as his experiments did not show that the salt gave an excessive value over the monochromate or other oxidizing agents. Furthermore, lower results were not obtained when the dissolved oxygen was expelled from the solution by carbon dioxide. Practically, theoretical results were obtained without using carbon dioxide. He claimed that all the differences that he detected were within the limits of experimental error.

Shorger ${ }^{3}$ did some work with potassium dichromate in 1908, the net outcome of which was a fair agreement with the work of Wagner. Even pure recrystallized dichromate always gave a higher value than it should, when used to oxidize hydriodic acid; but if the dissolved oxygen was removed by carbon dioxide the normal value was obtained. The measurements were done by ordinary volumetric methods.

Since potassium dichromate is so easily purified, ${ }^{4}$ and is so little affected by the ordinary conditions of handling, it seemed worth while to study its behavior as a standard in iodimetry by more precise methods of measurement, with the idea of comparing the results so obtained, with those of the average procedures in the standardization of thiosulfate solutions, and to this end the following experimental work was carried out:

\section{Preparation of Materials.}

Potassium Dichromate.-Two specimens of the salt were prepared,

1 Z. anorg. Chem., 19, 427 (1899).

$2 J$. prakt. Chem., 93, 73, 312 (1917).

${ }^{3}$ Unpublished thesis; work carried out at the Ohio State University under the direction of Prof. Foulk.

"Wagner, $Z$. anorg. Chem., 19, 427 (1899). Wagner found that he could start with the most impure dichromate obtainable and by 6 recrystallizations obtain a product which could not be purified farther by recrystallization. Baxter, THIS JouRNAL, 3I, $54 \mathrm{I}$ (I 909 ). In determining the atomic weight of chromium Baxter uses potassium dichromate 4 times crystallized, for the preparation of $\mathrm{Ag}_{2} \mathrm{Cr}_{2} \mathrm{O}_{7}$. 
using Kahlbaum's dichromate (prepared for analytical work) and Baker's analyzed dichromate, Each sample was recrystallized 4 times, the later recrystallizations being carried out in platinum ressels with the use of redistilled water. Great care was taken to protect the crystal crops from dust. A specimen of the salt was also prepared by the method of Meineke, ${ }^{1}$ but the product was not satisfactory, consequently it was not examined critically.

Iodine.-Since the oxidizing action of potassium dichromate was to be compared with that of pure iodine, it was necessary to have the latter substance in a high degree of purity as a reference material, to standardize the thiosulfate solutions. Baxter's ${ }^{2}$ method of purification was used. This involved the preliminary distillation of the commercial product from potassium iodide solution. It was then reduced to hydriodic acid with

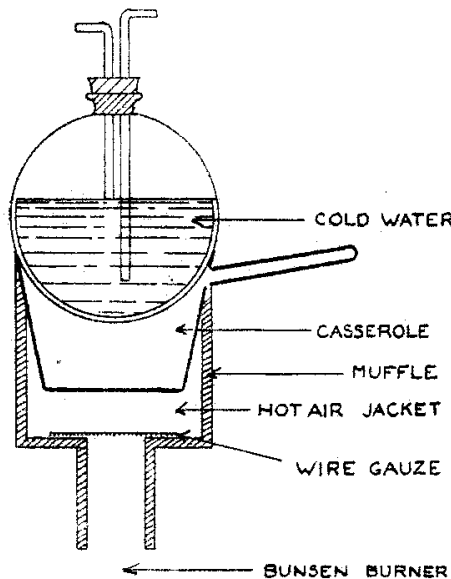

Fig. I loydrogen sulfide and the solution boiled until it approached the constant boiling mixture. The iodine was set free by distilling with potassium permanganate and the moist crystals were dried over sulfuric acid."

Iodine was also prepared by resubliming the commercial product, first with potassitum iodide, then 3 times without. (The apparatus illustrated in Fig. I was used.) This is a modification of the process described by 'Treadwell ${ }^{4}$ and differs from the original by the substitution of a casserole for the beaker and by the envelopment of the whole in a hot-air jacket, produced by heating the casserole in a muffle. Too often, when a beaker is used, as Treadwell suggests, water collects on the cold flask above, drops back into the hot beaker and breaks it. 'This trouble is obviated by the use of the casserole. The advantage of the hot air jacket is, that all of the iodine sublimes on the flask. In Treadwell's method quite a quantity of the sublimate adheres to the walls of the beaker. 'The apparatus described above was used successfully in subliming considerable quantities of iodine at a time--and very little was lost. The final product was carefully ground and dried over sulfuric acid and, in purity, it

1. Meineke, Ann., 357 (189I). Meineke prepared a pure sample by neutralizing a known quantity of chromic acid with potassium hydroxide, adding again the same quantity of chromic acid and recrystallizing 6 times.

2Baxter, Thrs Journal, 31, 201 (1909), "Atomic Weight of Iodine," Proc. Am. Acad, 40, 421 (rgo4).

${ }^{3}$ Baxter, This Journal, 32, I597 (I9IO).

4 'Treadwell and Hall, Analytical Chemistry, Vol. II, 507. 
was found to agree very closely with that which had been prepared by Baxter's method.

Sodium Thiosulfate Solution.-This solution was prepared by dissolving Merck's best quality of sodium thiosulfate in distilled water and allowing the solution to stand for nearly two months. The resulting solution was carefully siphoned from a small residue into a bottle that had been freed from carbon dioxide, and carefully protected from this gas by soda lime tubes.

Starch Solution.- - Kahlbaum's soluble starch was used for the indicator. The sensitiveness of the solution was found to decrease on standing a few days, so to avoid this a fresh solution was prepared every day.

Reagents $(a)$. - The hydrochloric acid used was carefully tested to see that it contained no substances that would liberate iodine. (b) Kahlbaum's potassium iodide was used, the same specimen being employed in all of the analyses. It was found to be free from iodates and substances that might liberate iodine.

Distilled Water.-Ordinary distilled water was redistilled through a block tin condenser and collected in a seasoned Jena flask. Only the middle half was saved, the first and last quarter being discarded. All flasks were steamed 5 to 20 minutes before using in the analytical work.

A method of subliming iodine into weighing tubes was necessary. Baxter, ${ }^{1}$ accomplished this by heating it in a hard glass tube in a current of dry air, and collecting the sublimate in a weighing tube. In trying to repeat this process difficulties were encountered. The iodine tended to sublime in the constricted end of the tube, clogging it, making constant watching and careful heating necessary. This apparatus was modified as illustrated in Fig. 2. The hard glass tube is encircled by a hot air jacket which is made by wrapping a larger tube with copper gauze. Th is

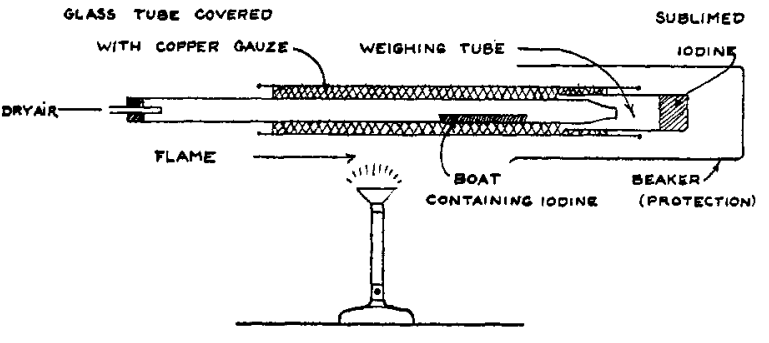

Fig. 2. developes a fairly constant temperature around the tube with the application of a small flame at one end. The weighing tube is slipped over the constricted end and is just covered at its opening by the hot-air jacket. The iodine sublimes, compactly, into the bottom of the tube which remains cool. Very little loss occurs in the process, so that the approximate weight of the iodine desired can be put into the boat in the hard glass tube. The apparatus needs little attention while in operation.

${ }^{1}$ Loc. cit. 
After sublimation the tubes are placed in a sand bath ( 120 to $130^{\circ}$ ) and the iodine fused and then put into a desiccator over sulfuric acid to cool.

After careful weighing by tares the tubes of iodine, with loosened stoppers, were allowed to slip into a liter Erlenmeyer flask containing $5 \mathrm{cc}$. of a concentrated solution of potassium iodide. The iodine was rapidly dissolved and the solution was made up to a volume of about $800 \mathrm{cc}$. The titration with the thiosulfate solution was made immediately, the greatest care being observed to avoid any loss in spray.

The main difficulty encountered in the use of pure iodine was to get it perfectly dry. Only after fusing as described above, was it found to give a constant set of values, which were not lowered by further drying. Two tables (I and II) are given to illustrate this situation. From Table II results were taken for the value of the thiosulfate solution used in most of the analyses of the dichromate samples. The solution was carefully checked from time to time and it was found that practically no deterioration took place during the period it was used.

\section{TABLE I.}

Standardization with Sublimed, Iodine.

Iodine was dried some weeks over sulfuric acid, sublimed into tubes, and placed in a desiccator over sulfuric acid for 24 hours.

\begin{tabular}{|c|c|c|c|}
\hline Wt. of iodine. & $\begin{array}{l}\mathrm{Na}_{2} \mathrm{~S}_{2} \mathrm{O}_{3} \text { solu- } \\
\text { tion } \text { required. }\end{array}$ & $\begin{array}{l}\text { Wt. of iodine } \\
\text { equal to one g. of } \\
\mathrm{Na}_{2} \mathrm{~S}_{2} \mathrm{O}_{3} \text { solutition. }\end{array}$ & $\begin{array}{l}\text { Wt. of } \mathrm{K}_{2} \mathrm{Cr}_{2} \mathrm{O}_{7} \\
\text { equal to one } \mathrm{g} \text {. } \\
\text { of thiosulfate. }\end{array}$ \\
\hline 0.51134 & 41.623 & 0.012285 & 0.004743 \\
\hline $0.6023 \mathrm{I}$ & 49.034 & 0.012283 & $\ldots$ \\
\hline 0.57854 & 47.106 & 0.012281 & $\cdots$ \\
\hline 0.50192 & 40.685 & 0.012282 & $\ldots$ \\
\hline $0.6188 \mathrm{I}$ & 50.396 & 0.012279 & $\ldots$ \\
\hline $0.5835^{8}$ & 47.511 & 0.012283 & $\ldots$ \\
\hline
\end{tabular}

TABLE II.

Standardization with Fused Iodine.

After subliming into tubes (Table I) iodine was fused and allowed to stand over sulfuric acid for 24 hours.

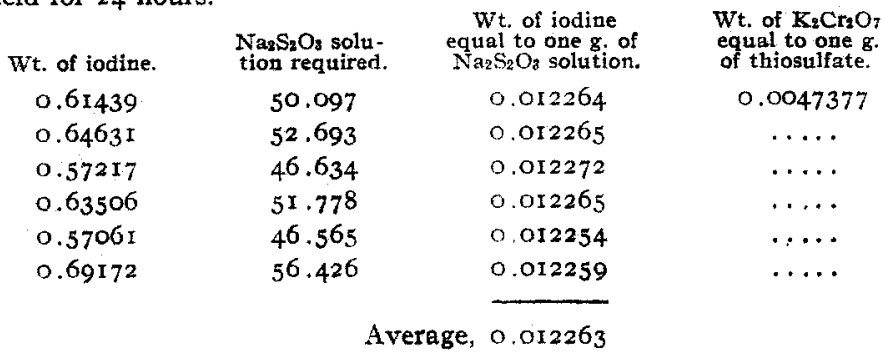

The value in the fourth column was obtained by calculation from the average of the values of the third column, and is used in the calculations in the tables following. 
In brief, the following procedure was used in analyzing potassium dichromate: The approximate weight of the sample desired was placed in a boat and fused in a bottling apparatus, which is a copy of that used by Foulk ${ }^{1}$ and Sweeney in their work on the standardization of a magnesium salt. The salt was fused, cooled, and bottled in a current of dry air, then accurately weighed, by the method of tares. The rule was to bring the sample just to the fusion point, and then the burners were lowered gradually.

This treatment insures uniformity in the character of the samples. inasmuch as all the moisture and any volatile impurities are removed. No evidence of decomposition was shown when the dichromate was held at the fusion point for 15 or 20 minutes, but this was not so with samples fused out in the air. In the latter case evidences of slight decomposition were often present. When samples were fused in a dusty atmosphere the evidences were more pronounced. All the experiments showed that it was safe to fuse the salt in the bottling apparatus in an atmosphere of pure dry air.

The sample, which was carefully weighed by calibrated weights, was transferred to a titrating flask, an ordinary liter Erlenmeyer flask especially fitted to admit carbon dioxide (Fig. 3). The titration was carried out by means of a weighing buret. About $0.2 \mathrm{~g}$. of the potassium dichromate was dissolved in the flask in approximately $800 \mathrm{cc}$. of water. Carbon dioxide in a spray of small bubbles was passed through the solution for one-half hour. Provision was made so there could be no loss in a liquid spray. The stream of carbon dioxide was then turned off and the solution was acidified with hydrochloric acid,

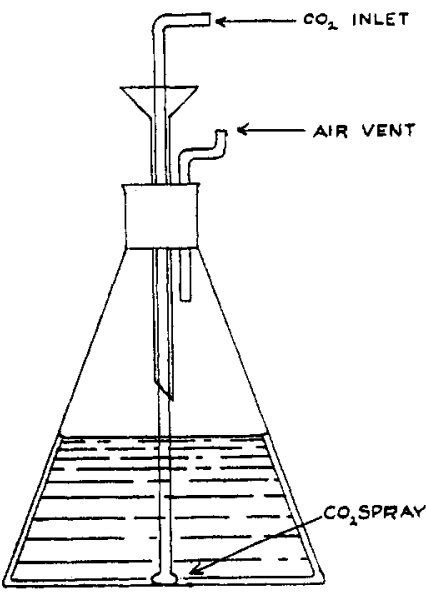

Fig. 3. and potassium iodide was added. The flask was thoroughly shaken during the titration.

In Table III are given the results obtained in the analyses of Baker's analyzed dichromate. The sample used was not recrystallized, nor was carbon dioxide bubbled through the solutions. In the second column the actual weights of the salt employed are given, while the corresponding weights of thiosulfate solution required appear in the first column. In the third column are the calculated weights of potassium dichromate obtained by multiplying the weight of the thiosulfate solution in $\mathrm{g}$. by the weight of dichromate equivalent to one $\mathrm{g}$. of this solution as determined

2 Foulk and Sweeney, ThIs Journal, 36, 2360-72 (1914). 
by its standardization with pure iodine. Column 4 gives the percentage by which the calculated weight exceeds the actual weight.

In Table IV are given the results obtained from the analyses of Baker's analyzed dichromate after being 4 times recrystallized. Carbon dioxide was not bubbled through the solutions. Comparing the average of the results obtained $(0.33 \%)$ with that of Table III $(0.59 \%)$, we see the effect of recrystallization. Recrystallization alone, however, is not sufficient to produce the theoretical value.

In 'Table $V$ are given a few values obtained by the use of Baker's analyzed dichromate which had not been recrystallized. Carbon dioxide was bubbled through the solutions. Comparing the average value $(0.22 \%)$ with that of Table III $(0.59 \%)$, the effect of the use of carbon dioxide is noted.

\section{TABLE III.}

Analyses of Samples of Baker's Analyzed $\mathrm{K}_{2} \mathrm{Cr}_{2} \mathrm{O}_{7}$. Not Recrystallized. Without the use of $\mathrm{CO}_{2}$.

\begin{tabular}{|c|}
\hline $\begin{array}{l}\text { Wt. of } \mathrm{Naz}_{2} \mathrm{C} \\
\text { solution. }\end{array}$ \\
\hline 52.680 \\
\hline 39.019 \\
\hline 41.913 \\
\hline 51.732 \\
\hline 47.124 \\
\hline 42.070 \\
\hline 41.430 \\
\hline
\end{tabular}

Actual wt. of
f11sed $\mathrm{K}_{2} \mathrm{Cr}_{2} \mathrm{O}_{7}$
0.24867
0.18395
0.19770
0.24347
0.22222
0.19808
0.19433

$\begin{array}{cc}\begin{array}{c}\text { Calc. wt. } \\ \text { of } \mathrm{K}_{2} \mathrm{Cr}_{2} \mathrm{O}_{3}\end{array} & \begin{array}{c}\text { \% calc. wt. ex } \\ \text { ceeds actual w }\end{array} \\ 0.24960 & 0.40 \% \\ 0.18487 & 0.50 \\ 0.19858 & 0.45 \\ 0.24510 & 0.67 \\ 0.22327 & 0.48 \\ 0.19932 & 0.63 \\ 0.19629 & 1.00 \\ & - \\ & \text { Average, } 0.59\end{array}$

TABLE IV.

Analyses of Samples of Baker's Analyzed Dichromate after 4 Recrystallizations. Without use of $\mathrm{CO}_{2}$.

$\begin{array}{cccc}\begin{array}{c}\text { Wt. of } \mathrm{Na}_{2} \mathrm{~S}_{2} \mathrm{O}_{3} \\ \text { solution. }\end{array} & \begin{array}{c}\text { Actual wt. of } \\ \text { fused } \mathrm{K}_{2} \mathrm{Cr}_{2} \mathrm{O}_{7} .\end{array} & \begin{array}{c}\mathrm{Calc} . \mathrm{wt} . \\ \text { of } \mathrm{K}_{2} \mathrm{Cr}_{2} \mathrm{O}_{7} .\end{array} & \begin{array}{c}\text { \% calc. wt. ex- } \\ \text { ceeds actual wt. }\end{array} \\ 44.983 & 0.21246 & 0.213 \mathrm{I} 2 & 0.3 \mathrm{I} \\ 46.12 \mathrm{I} & 0.21805 & 0.21852 & 0.2 \mathrm{I} \\ 40.707 & 0.1922 \mathrm{I} & 0.19286 & 0.34 \\ 48.1 \mathrm{II} & 0.227 \mathrm{O} 4 & 0.22794 & 0.4 \mathrm{O} \\ 47.452 & 0.22383 & 0.22483 & 0.44 \\ 48.197 & 0.22729 & 0.22835 & 0.42 \\ 44.394 & 0.2095 \mathrm{I} & 0.21034 & 0.40 \\ 47.475 & 0.2244 \mathrm{I} & 0.22495 & 0.24 \\ 49.097 & 0.23208 & 0.23262 & 0.24 \\ 47.266 & 0.22349 & 0.22394 & 0.20 \\ 45.673 & 0.21543 & 0.21639 & 0.44 \\ 49.306 & 0.23247 & 0.2336 \mathrm{I} & 0.49 \\ 47.818 & 0.22591 & 0.22656 & 0.28 \\ 45.436 & 0.21458 & 0.2 \times 527 & 0.27 \\ & & & \end{array}$


TABLE V.

Analyses of Samples of Baker's Analyzed Dichromate. Not Recrystallized. $\mathrm{CO}_{2}$ Bubbled into Solutions.

\begin{tabular}{|c|c|c|c|}
\hline $\begin{array}{l}\text { Wt. of } \mathrm{Na}_{2} \mathrm{Na}_{2} \mathrm{O}_{3} \\
\text { solution. }\end{array}$ & $\begin{array}{l}\text { Actual wht. of } \\
\text { fused } \mathrm{K}_{2} \mathrm{Cr}_{3} \mathrm{O}_{7} \text {. }\end{array}$ & $\begin{array}{l}\text { Calc. wt. } \\
\text { of } \mathrm{K}_{2} \mathrm{Cr}_{2} \mathrm{O}_{7} \text {. }\end{array}$ & $\begin{array}{l}\% \text { calc. wt. ex- } \\
\text { ceeds actual wt. }\end{array}$ \\
\hline 42.552 & $0.2016 \mathrm{I}$ & 0.20164 & 0.23 \\
\hline 41.764 & 0.19818 & 0.19787 & 0.08 \\
\hline $45 \cdot 426$ & 0.21499 & 0.21522 & 0.34 \\
\hline 44.2 II & 0.20946 & 0.20947 & 0.23 \\
\hline
\end{tabular}

Table VI shows the effect of expelling the air by passing carbon dioxide through the solutions. A sample of Baker's dichromate that had been recrystallized 4 times, was used. This series without carbon dioxide (Table IV) gave a value of $0.33 \%$ high. In Table VI carbon dioxide was passed through the solutions for various lengths of time (5-10-I 5-30 min.). For short lengths of time variable results were obtained, but for 30 min. or longer an average value of $0.015 \%$ below the theoretical, was obtained. Thus by passing in carbon dioxide for a proper length of time the values are practically corrected.

\section{TABLE VI.}

Analyses of Baker's Dichromate. Four Times Recrystallized. $\mathrm{CO}_{2}$ Pasced through Solutions.

\begin{tabular}{|c|c|c|c|c|}
\hline $\begin{array}{l}\text { Wt. of } \mathrm{Na}_{2} \mathrm{~S}_{2} \mathrm{O}_{3} \\
\text { solution. }\end{array}$ & $\begin{array}{l}\text { Actual }{ }^{w t} \text { of } \\
\text { fused } \mathrm{K}_{2} \mathrm{Cr}_{2} \mathrm{O}_{7}\end{array}$ & $\begin{array}{l}\text { Calc. wt. } \\
\text { of } \mathrm{K}_{2} \mathrm{Cr}_{2} \mathrm{O} \text {. }\end{array}$ & $\begin{array}{l}\% \text { calc. wt } \\
\text { ceeds actua }\end{array}$ & \multirow{7}{*}{$\mathrm{CO}_{2} 5-10-20 \mathrm{~min}}$. \\
\hline 44.851 & 0.22197 & 0.21250 & 0.25 & \\
\hline 54.603 & 0.25826 & 0.25870 & 0.18 & \\
\hline 49.128 & 0.23215 & 0.22276 & 0.27 & \\
\hline 42.290 & 0.20029 & 0.20037 & 0.04 & \\
\hline 48.567 & 0.22969 & 0.23011 & 0.19 & \\
\hline \multirow[t]{2}{*}{42.346} & 0.20055 & 0.20063 & 0.04 & \\
\hline & \multicolumn{4}{|c|}{ Average, 0.16} \\
\hline 49.276 & 0.23346 & 0.23346 & 0.00 & \multirow{8}{*}{$\mathrm{CO}_{2} 30 \mathrm{~min}$. or longer. } \\
\hline $44.33 I$ & 0.20996 & 0.21004 & 0.03 & \\
\hline 47.028 & $0.2229 \mathrm{I}$ & 0.22282 & -0.04 & \\
\hline $50.55^{8}$ & 0.23955 & 0.23954 & 0.00 & \\
\hline 50.186 & 0.23794 & $0.2377^{8}$ & $\multimap 0.06$ & \\
\hline 50.210 & 0.23780 & $0.237^{89}$ & 0.03 & \\
\hline 50.995 & 0.24190 & $0.24 I 6 I$ & -0.10 & \\
\hline 50.640 & 0.23994 & 0.23993 & 0.00 & \\
\hline
\end{tabular}

It was proposed to use other indifferent gases to see if they would have the same corrective effect as carbon dioxide. Hydrogen was tried, the gas being bubbled through solutions of Baker's purified samples. The results given in Table VII were obtained, showing an average value of $0.07 \%$ above the theoretical. Hydrogen has the corrective effect, but 
the average is not as near the theoretical as the carbon dioxide value. Possibly this may be due to the fact that the oxygen in the solutions is expelled more slowly by hydrogen than by carbon dioxide. At any rate both gases effect a marked correction compared with the same sample, analyzed without the expulsion of dissolved air.

TABLE VII.

Baker's Dichromate. Recrystallized 4 Times. Hydrogen Passed through the Solutions for 30 Minutes.

Wt. of $\mathrm{NgS}_{2} \mathrm{O}_{3}$
solution.
49.044
$44.54 \mathrm{I}$
$41.2 \mathrm{II}$
53.345
46.520
47.231

$\begin{gathered}\text { Actual wt. of } \\ \text { fused } \mathrm{K}_{2} \mathrm{Cr}_{2} \mathrm{O}\end{gathered}$
0.23216
0.21103
$0.1949 \mathrm{I}$
$0.2526 \mathrm{I}$
0.22032
0.22362

Calc. $\mathrm{wt}_{\text {t. }}$
of $\mathrm{K}_{2} \mathrm{Cr}_{2} \mathrm{O}_{7}$
0.23237
0.21103
0.19525
0.25274
0.22041
0.22378

\% calc. wt. exceeds actual $w t$.

$\begin{array}{r}0.09 \\ 0.00 \\ 0.17 \\ 0.05 \\ 0.04 \\ 0.07 \\ \text { Average, } \\ \hline\end{array}$

Conditions were now exaggerated by bubbling oxygen through the solutions previous to the analysis, and widely varying values were obtained. An average of $0.33 \%$ was obtained, as shown by Table VIII. The irregular values might be explained by the presence of varying amounts of oxygen in the solutions. Excessively high values may be due to the presence of some ozone. It is apparent that the presence of oxygen has something to do with the conduct of the dichromate.

TABLE VIII.

Baker's Dichromate. Recrystallized. Oxygen Gas Bubbled through Solutions for 30 Minutes.

$\begin{array}{cccc}\begin{array}{c}\text { Wt. of } \mathrm{Na}_{2} \mathrm{~S}_{2} \mathrm{O}_{3} \\ \text { solution. }\end{array} & \begin{array}{c}\text { Actual } \\ \text { fused. of } \mathrm{K}_{2} \mathrm{Cr}_{2} \mathrm{O}_{7}\end{array} & \begin{array}{c}\mathrm{Calc}_{.} \text {wt. } \\ \text { of } \mathrm{K}_{2} \mathrm{Cr}_{2} \mathrm{O}_{7}\end{array} & \begin{array}{c}\text { \% calc. wt. ex- } \\ \text { ceeds actual wt. }\end{array} \\ 41.287 & 0.19520 & 0.1956 \mathrm{I} & 0.21 \\ 42.19 \mathrm{I} & 0.19868 & 0.19990 & 0.6 \mathrm{I} \\ 43.487 & 0.20522 & 0.20604 & 0.40 \\ 46.529 & 0.21855 & 0.22045 & 0.87 \\ 43.908 & 0.20787 & 0.20803 & -0.07 \\ 44.780 & 0.21215 & 0.21216 & 0.00 \\ 44.036 & 0.20813 & 0.20864 & 0.24 \\ 47.968 & 0.22633 & 0.22727 & 0.42 \\ 44.841 & 0.21173 & 0.21246 & 0.34 \\ 45.518 & 0.21490 & 0.21566 & 0.30 \\ 49.350 & 0.23305 & 0.23382 & 0.35 \\ & & & \text { Average, } 0.33\end{array}$

A sample of Kahlbaum's potassium dichromate was now recrystallized in the same careful manner as was the Baker's sample. Results are shown in Tables IX and X, with and without the use of carbon dioxide, respectively. After the first irregularities, which were probably due to experimental errors, the values settle down to an average which differs only 
by $0.03 \%$. The carbon dioxide series is $0.08 \%$ above the theoretical, while the samples containing dissolved air form a series a little above this one. The sample gives practically the same average results when the oxygen is present in the solution and when it has been expelled. Certainly Kahlbaum's sample differs markedly from Baker's in this respect. Possibly the presence of minute traces of some substance, catalytic in nature, may be present in Baker's sample. Recrystallization, evidently, does not remove it. The absence of this substance may account for the more nearly normal reactions of Kahlbaum's sample. The different results of Wagner and Bruhns may be accounted for in the same way. The sample used by Bruhns may have been free from the impurity that exerted the catalytic effect. What this impurity is, is an open question. If such is the case, it is to be hoped that a method for its identification and removal may be forthcoming.

TABLE IX.

Kahlbaum's Dichromate. 4 Times Recrystallized. $\mathrm{CO}_{2}$ Passed in for 30 Minutes.

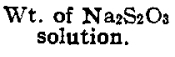

52.715

49.135

52.157

48.210

52.044

49.652

$49 \cdot 105$

48.736

48.815

47.179

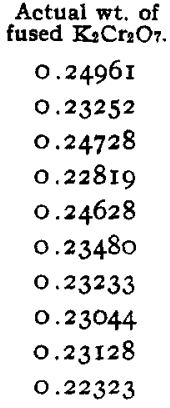

Actual wt. of
tused $\mathrm{K}_{2} \mathrm{Cr}_{2} \mathrm{O}_{7}$.

$0.2496 \mathrm{I}$

0.23252

0.24728

$0.228 \mathrm{I} 9$

0.24628

0.23480

0.23044

0.22323
$\mathrm{Calc}$ wt.
of $\mathrm{K}_{2} \mathrm{Cr}_{2} \mathrm{O}_{7}$.

0.24976

0.23280

0.247 I I

$0.2284 \mathrm{I}$

0.24658

0.23525

0.23265

0.23091

0.23128

0.22353
$\%$ calc. wt. exceeds actual $\mathrm{wt}$.

0.06

0.12

$-0.06$

0.09

0.12

0.19

0.13

0.10

0.00

0.09

Average, 0.08

TABLE X.

Kahlbaum's Dichromate. 4 Times Recrystallized. Without Use of $\mathrm{CO}_{2}$.

$\begin{array}{cc}\begin{array}{c}\text { Wt. of } \mathrm{Na}_{2} \mathrm{~S}_{2} \mathrm{O}_{3} \\ \text { solution. }\end{array} & \begin{array}{c}\text { Actual wt. of } \\ \text { fused } \mathrm{K}_{2} \mathrm{Cr}_{2} \mathrm{O}_{7}\end{array} \\ 56.04 \mathrm{I} & 0.26483 \\ 50.289 & 0.23767 \\ 49.193 & 0.23258 \\ 54.683 & 0.25894 \\ 47.862 & 0.22655 \\ 54.000 & 0.25585 \\ 50.526 & 0.23939\end{array}$

Calc. wt.

of $\mathrm{K}_{2} \mathrm{Cr}_{2} \mathrm{O}$.

0.26552

0.23826

0.23307

0.25908

0.22677

$0.255^{85}$

0.23939
$\%$ calc. wt. ex-

ceeds actual $\mathrm{wt}$.

0.26

$0.2 I$

$0.2 \mathrm{I}$

0.05

0.10

$0 . \infty$

$0 . \infty$

Average, $0.1 \mathrm{I}$

An attempt was made at this point to demonstrate the presence of an impurity by making melting-point determinations. A simple scheme was devised for carrying out this work. Anhydrous 'zinc chloride was found to melt to a clear liquid, easily stirred, above $300^{\circ}$. Melting points 
were easily determined by the ordinary method, which were not sufficiently refined to show the difference, if any, in the purified samples of dichromate. The effects of recrystallization, however, were plainly demonstrable. By this method the following melting points were obtained for two samples of potassium dichromate:

$\begin{array}{cc}\text { MELTING PoINTS OF BakeR's ANALYZed Dichromate. } \\ \text { Original. } \\ 392^{\circ} & 3 \text { times recrystallized. } \\ 392 & 397^{\circ} \\ 394 & 397 \\ 392 & \ldots\end{array}$

The method is promising for determining melting points between 300 and $400^{\circ}$.

It seemed desirable to compare fused samples of the dichromate with dried samples. Table IV shows the results obtained from a series of fused samples and Table XI shows the results obtained by drying the dichromate for one hour at $130^{\circ}$, the temperature ordinarily used. Both series of

TABLE XI.

Baker's Dichromate. \& Times Recrystallized. Without Use of $\mathrm{CO}_{2}$. Samples Lried.

$\begin{array}{cccc}\begin{array}{c}\text { Wt. of } \mathrm{Na}_{2} \mathrm{~S}_{2} \mathrm{O}_{3} \\ \text { solution. }\end{array} & \begin{array}{c}\text { Actual wt. of } \\ \text { dichromate dried at } \\ 130^{\circ} \text { for one hour. }\end{array} & \begin{array}{c}\text { Calc. wt. } \\ \text { of } \mathrm{K}_{2} \mathrm{Cr}_{2} \mathrm{O}_{2}\end{array} & \begin{array}{c}\text { \% calc. wt. ex- } \\ \text { ceeds actual wt. }\end{array} \\ 46.506 & 0.21978 & 0.22034 & 0.26 \\ 44.085 & 0.20818 & 0.20887 & 0.30 \\ 54.603 & 0.25826 & 0.25870 & 0.18 \\ 43.319 & 0.20486 & 0.20524 & 0.14 \\ 43.908 & 0.20787 & 0.20803 & 0.08 \\ 43.446 & 0.20565 & 0.20584 & 0.10 \\ 51.648 & 0.24392 & 0.24470 & 0.32 \\ 47.553 & 0.22471 & 0.22530 & 0.26 \\ 49.298 & 0.23329 & 0.23357 & 0.12 \\ 47.449 & 0.22452 & 0.22481 & 0.13 \\ 51.542 & 0.24395 & 0.24420 & 0.10 \\ 49.820 & 0.23559 & 0.23604 & 0.19 \\ 45.989 & 0.21748 & 0.21789 & 0.18 \\ & & & \text { Average, } \\ & & & \end{array}$

results were obtained without bubbling carbon dioxide through the solutions, thus we get with the Baker's sample, as we expected, higher values than the theoretical. The fused specimen gives a higher average than the one that was dried. The complete loss of water and volatile substances may account for the higher values of the former. It is to be remembered that the value of the fused samples comes down practically to the theoretical when the air is expelled from the solutions with the carbon dioxide.

It is known that the action of the light rays brings about a slow de- 
composition of hydriodic acid in solution. It was noticed that the blue color returned rather rapidly when flasks, in which the end point had been reached, were placed in the direct sunlight. All titrations were carried out in indirect light, to avoid any error from this source. Some experiments were run which seem to show that the decomposition is roughly proportional to the intensity of the light. Three sets of solutions were made up containing the same concentration of potassium iodide. To one, chromium chloride was added and then acidified. The purpose was to find out if this salt had anything to do with the after liberation of iodine. The second set of solutions contained acidified potassium iodide and the third set potassium iodide alone. Starch was added to all of the solutions and they were placed in Nessler tubes and exposed to different intensities of sunlight. Table XII contains a summary of the results.

TABLE XII.

Action of Light on Solutions Containing Hydriodic Acid.

Bright sunlight Indirect sun- Shadow,

Dark cabinet, one hr.

1. $\mathrm{KI}, \mathrm{CrCl}_{3}$, starch.. Deep blue Color $1 / 2$ as in-Very faint No color. Faint blue tense blue after I 2 hrs.

II. KI, HCl, starch.... Same depth of color as in Series I.

III. KI, starch....... No color No color No color No color

Apparently, the after liberation of iodine is due to light, and not to $\mathrm{CrCl}_{3}$ or any other substance present.

In closing the writer desires to express his thanks to Prof. C. W. Foulk, of the Ohio State University, at whose suggestion this investigation was undertaken.

\section{Summary.}

It was noticed in this work that a concordant series of results was not obtainable in solutions containing dissolved oxygen. The irregularities of the results show this. In every case, however, when dissolved air was washed out with indifferent gases, values agreeing more closely with each other were obtained.

The results of this work show:

I. That some samples of dichromate give higher oxidation values than the theoretical when analyzed under ordinary conditions.

II. That the removal of dissolved air with indifferent gases acts as a corrective.

III. That there was one sample of dichromate which did not show this high value and the removal of dissolved air with indifferent gases produced only a small effect.

IV. The probable presence of an impurity in some samples of dichromate which is not removed by recrystallization. 
$V$. The effect of recrystallization on the purity of samples of the salt.

VI. The relative effect of drying and fusing samples of dichromate.

Conumbus, BHich.

NOTE.

Scandium from a Brazilian Source (Preliminary Announcement).While working upon zirconium, the writer observed that certain hydroxides from residues from which the most strongly basic elements had been removed, and which consisted mainly of iron, aluminium and titanium, dissolved in hydrofluoric acid imperfectly owing to the formation of a gelatinous substance. Several grams of this were collected and boiled for some time with concd. sulfuric acid in a platinum dish. The cooled residue dissolved readily even in hot water. The sulfate solution gave a precipitate with oxalic acid, and the oxalate upon ignition gave a pale yellowish oxide. The solution in hydrochloric acid showed no absorption spectrum. The dilute chloride solution was rapidly precipitated by boiling with sodium thiosulfate. Oxalic acid gave no precipitate when heated with the original hydroxides dissolved in hydrochloric acid. These reactions prove conclusively that the gelatinous precipitate first formed consisted mainly of scandium fluoride.

The above residues were obtained from Brazilian zirconia. At the present time there may be a little delay before work upon a large number of varieties of zirconium minerals is undertaken. C. JAMES.

DURHAM, N. H.

[CONTRIBUtION FROM THE DIVISION OF Chemistry, HARVARd UNIVERSITY.]

\title{
THE CONFIGURATIONS OF ORGANIC COMPOUNDS AND THEIR RELATION TO CHEMICAL AND PHYSICAL PROPERTIES. II.
}

\author{
By ARTHUR Michater. \\ Received March 25, 1918
}

In this paper the physical and chemical properties of the stereomeric, unsaturated acids will be coördinated with the configurations given in the first communication, ${ }^{1}$ as far as the experimental observations at hand permit, with a critical revision of previous views in this field.

Owing to the imperfect and inadequate experimental data, a perfectly satisfactory treatment of the subject is not possible at present; even in the few existing systematic investigations, not infrequently the members of the series most important from the riewpoint of theory were omitted, as beyond the scope of researches.

1 ThIs JorRNal, 40, 704 (1918). 